\title{
Optimal 3D Deployment and Trajectory Selection of UAVs for Maximum Network Utility and Disaster Management
}

Sanjoy Debnath ( $\sim$ sanjoydebnath80@gmail.com )

National Institute of Technology Silchar https://orcid.org/0000-0002-3169-5613

Wasim Arif

NIT Silchar: National Institute of Technology Silchar

Debarati Sen

IIT Kharagpur: Indian Institute of Technology Kharagpur

Srimanta Baishya

NIT Silchar: National Institute of Technology Silchar

\section{Research Article}

Keywords: Unmanned Aerial Vehicle (UAV), Optimal UAV Deployment, Algorithm, Trajectory Selection, Hybrid DE

Posted Date: May 7th, 2021

DOI: https://doi.org/10.21203/rs.3.rs-497805/v1

License: (9) This work is licensed under a Creative Commons Attribution 4.0 International License. Read Full License 


\section{Abstract}

Advancement in Unmanned Aerial Vehicles (UAV) technology supervised us to use them in many situations like seismic survey of an area, border and restricted area surveillance, disaster rescue, agriculture monitoring, and many others. The deployment of UAVs for expansion and extension of wireless network coverage for surveillance and rescue during and post disaster situations is fenced with promising challenges. The dense user coverage, quality of service (QoS), user data rate requirement, limited short flying time, and optimal trajectory path are some of the pertinent issues that UAVs are encountering. In this work we develop some algorithms for fast deployment of UAVs for application in disaster scenarios and optimal trajectory of each UAV in some specified area. The main aim of the work is to reduce the time complexity for optimal deployment of UAVs in order to optimize diverse parametric constraints. We propose a highly time efficient algorithm for UAV deployment through Lloyd and FCM as the initial localization of position in conjunction with the evolutionary algorithm namely Differential Evolution (DE) and Hybrid Differential Evolution with Learning (HDEL) for finding the optimal location of UAVs. We also develop an algorithm for finding out the optimal trajectory to reach the intended location for effective deployment of UAVs to ensure optimal resource allocation and user coverage.

Comprehensive simulation of various performance measuring metrics is obtained and the result shows that the proposed algorithms are well efficient as compared to some of the standard algorithms used in deployment of UAVs.

\section{Full Text}

This preprint is available for download as a PDF.

\section{Figures}

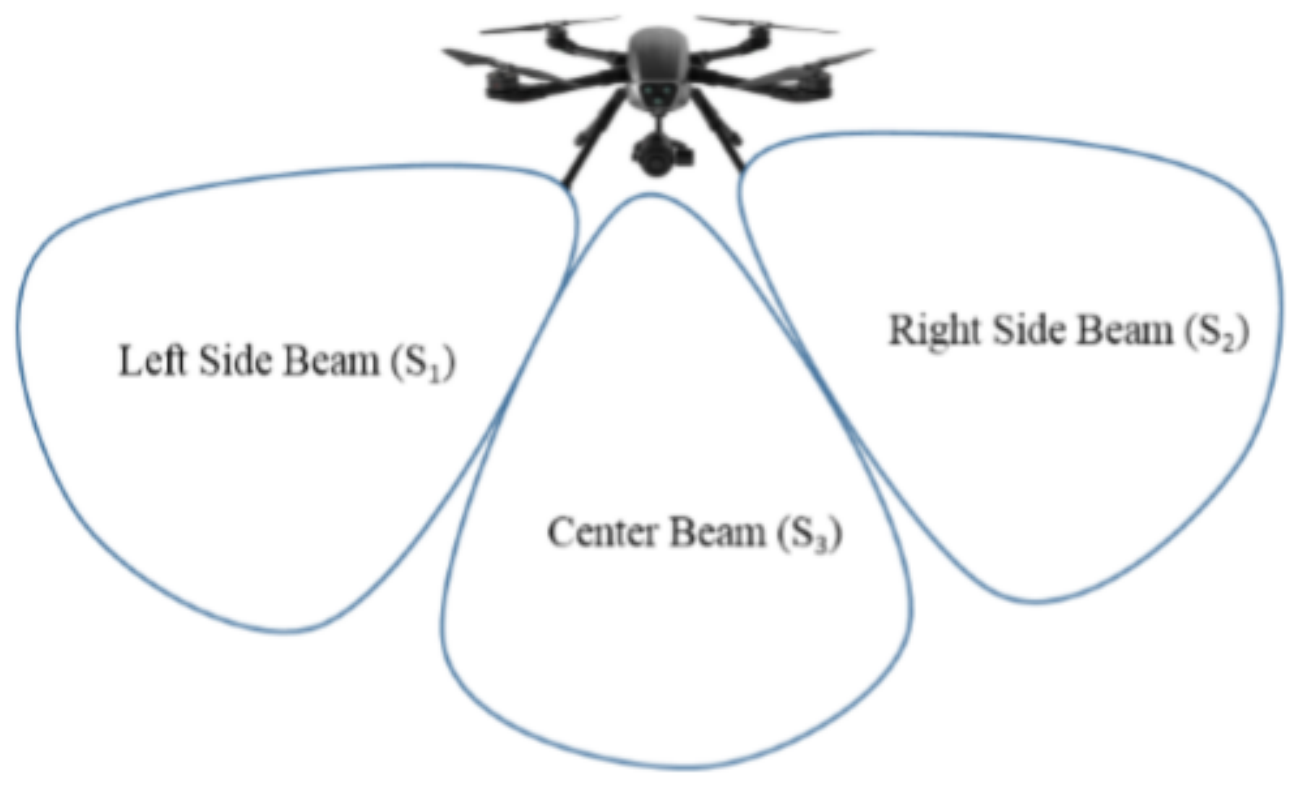

Figure 1 
UAV array antenna radiation in far field

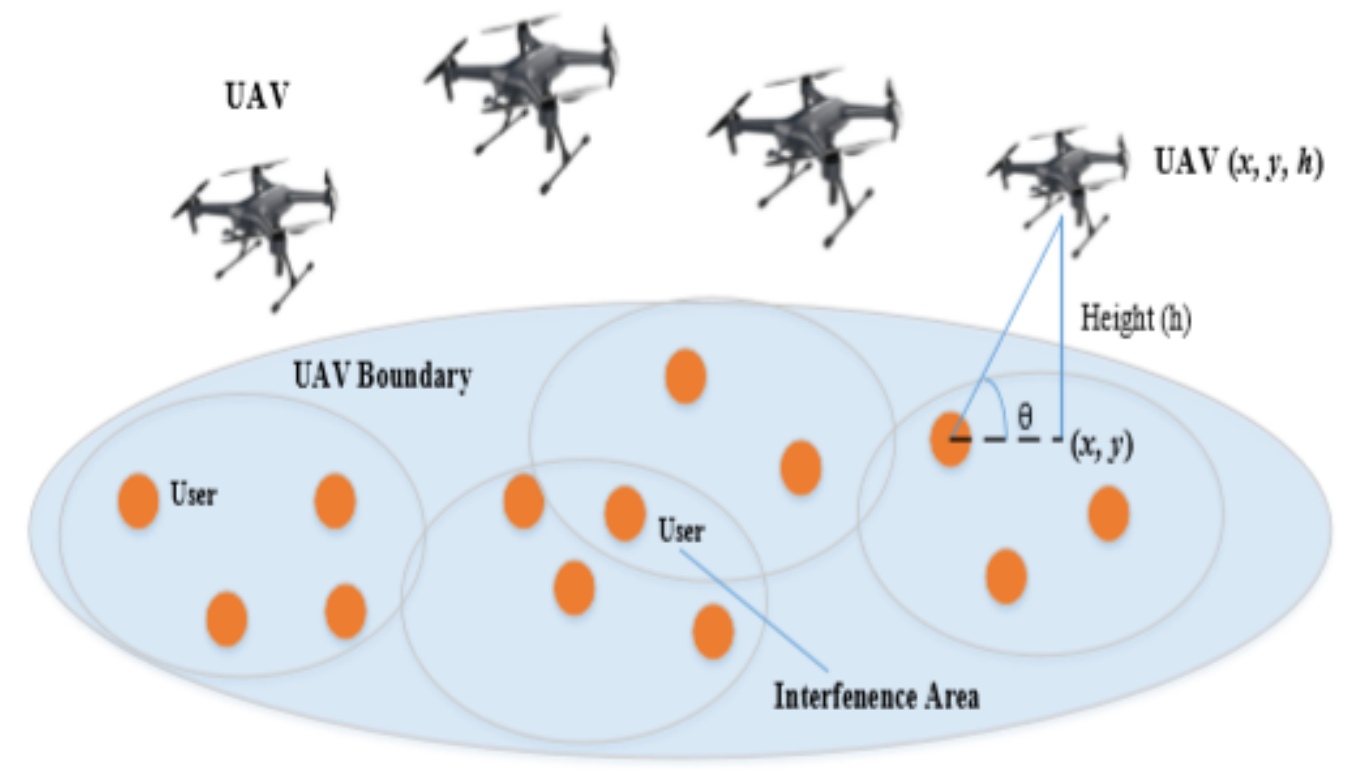

Figure 2

Interference area localization

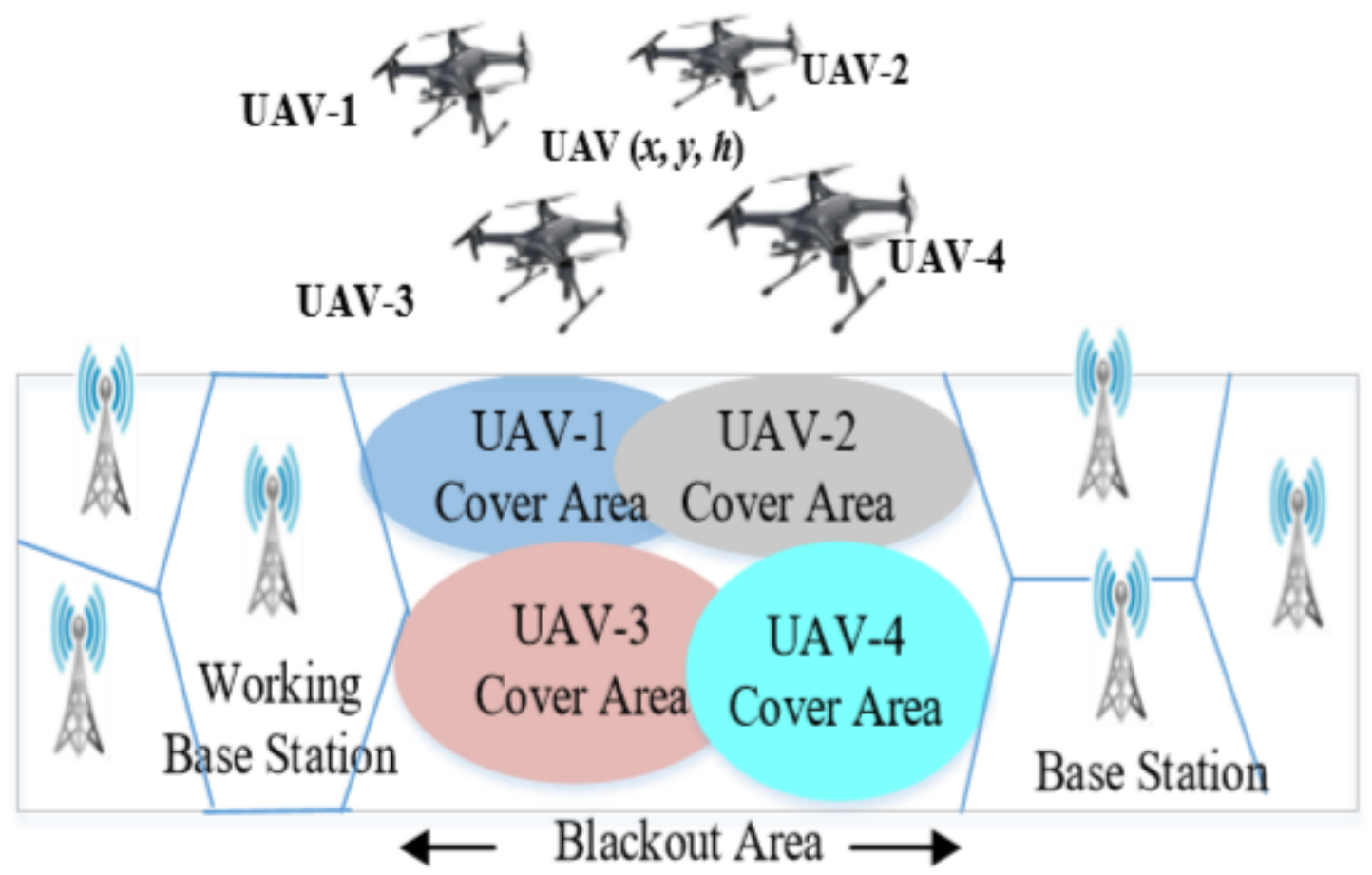

Figure 3

Created blackout area coverage with the deployment of drone 

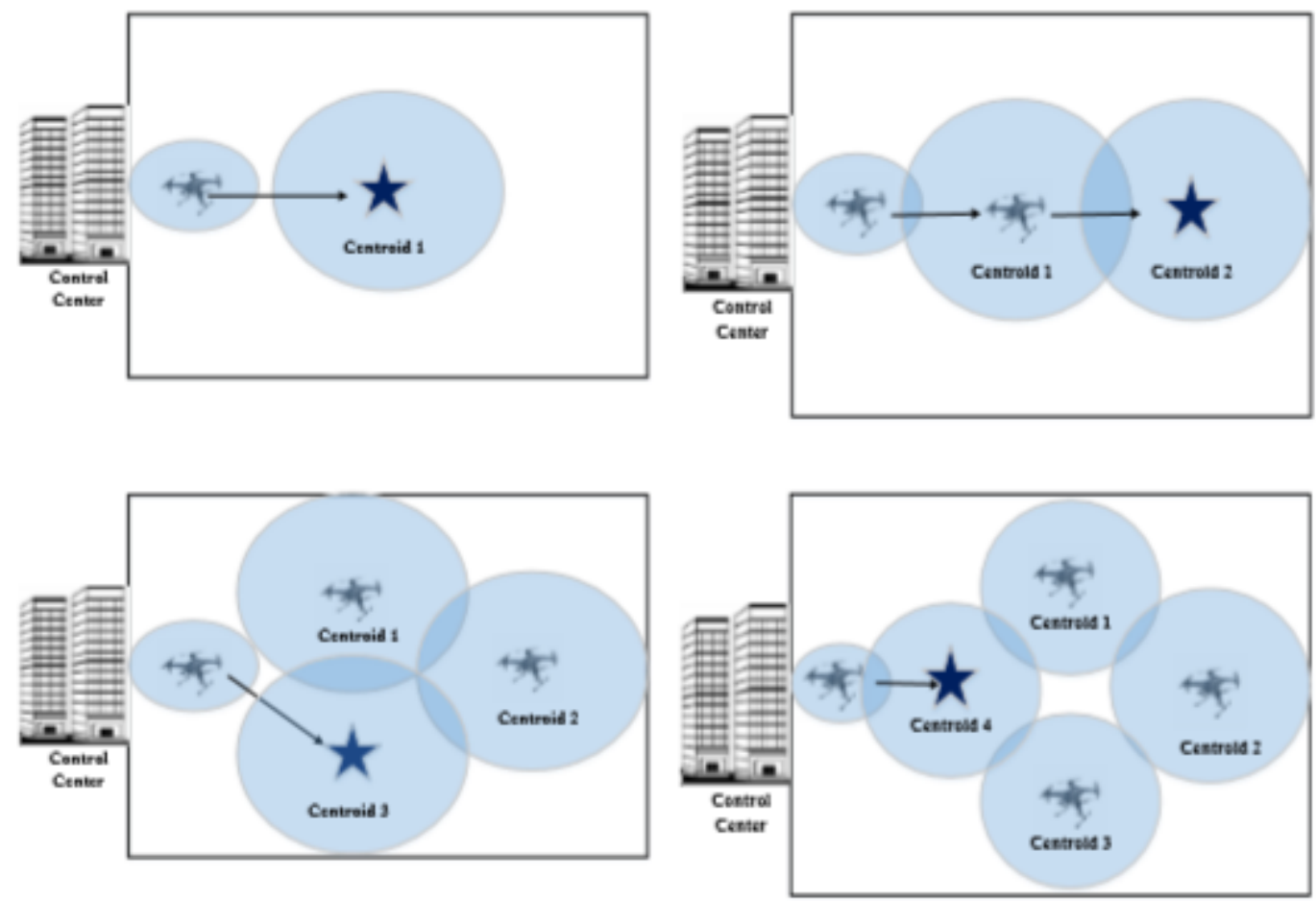

Figure 4

System model to find the trajectory path of UAV

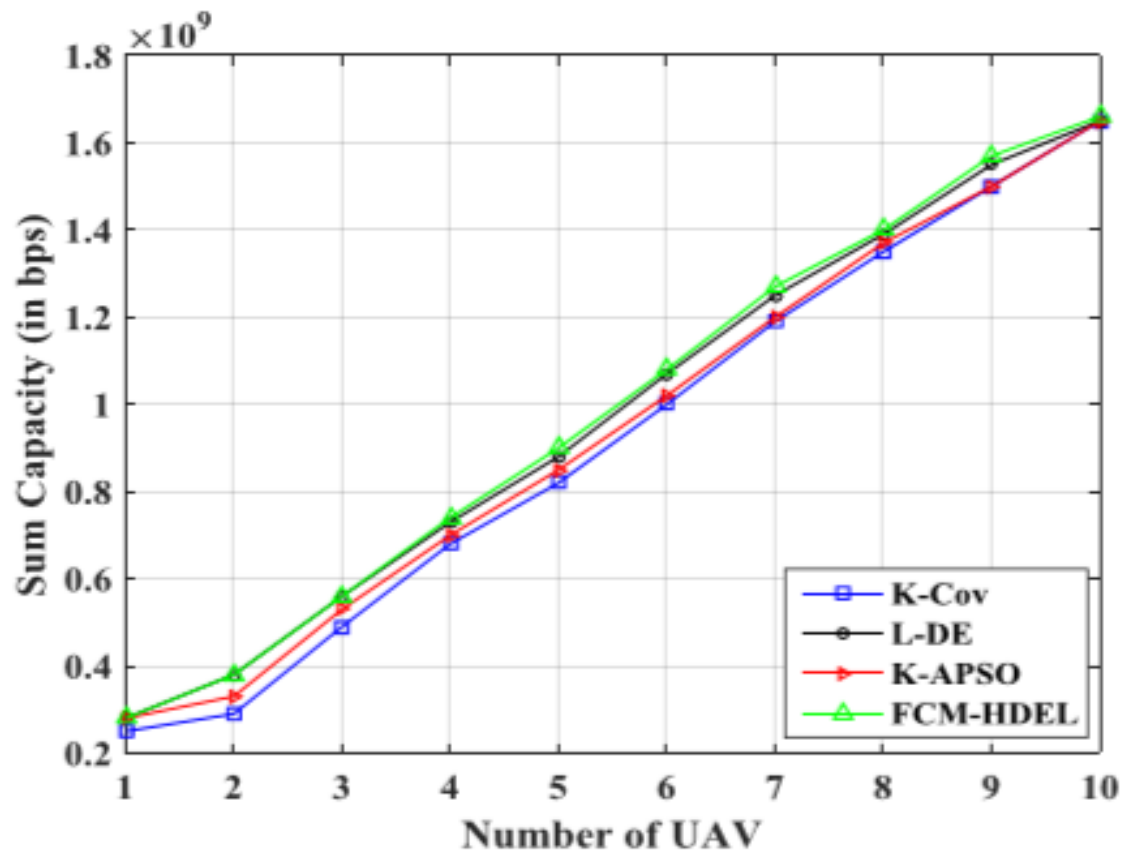

Figure 5

Number of UAV deployed versus Sum capacity of the network 


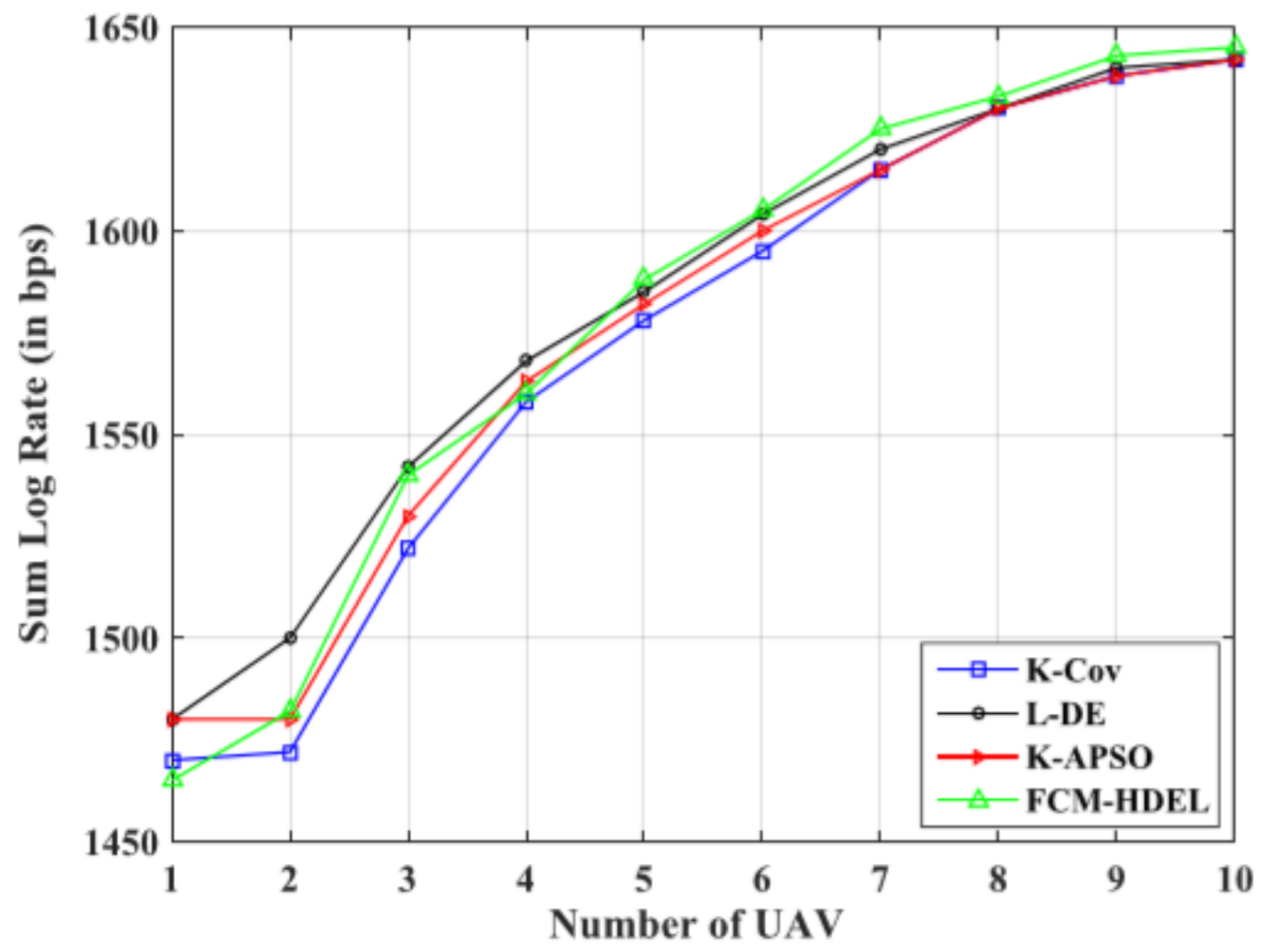

Figure 6

Number of UAV deployed versus Sum log rate of the network

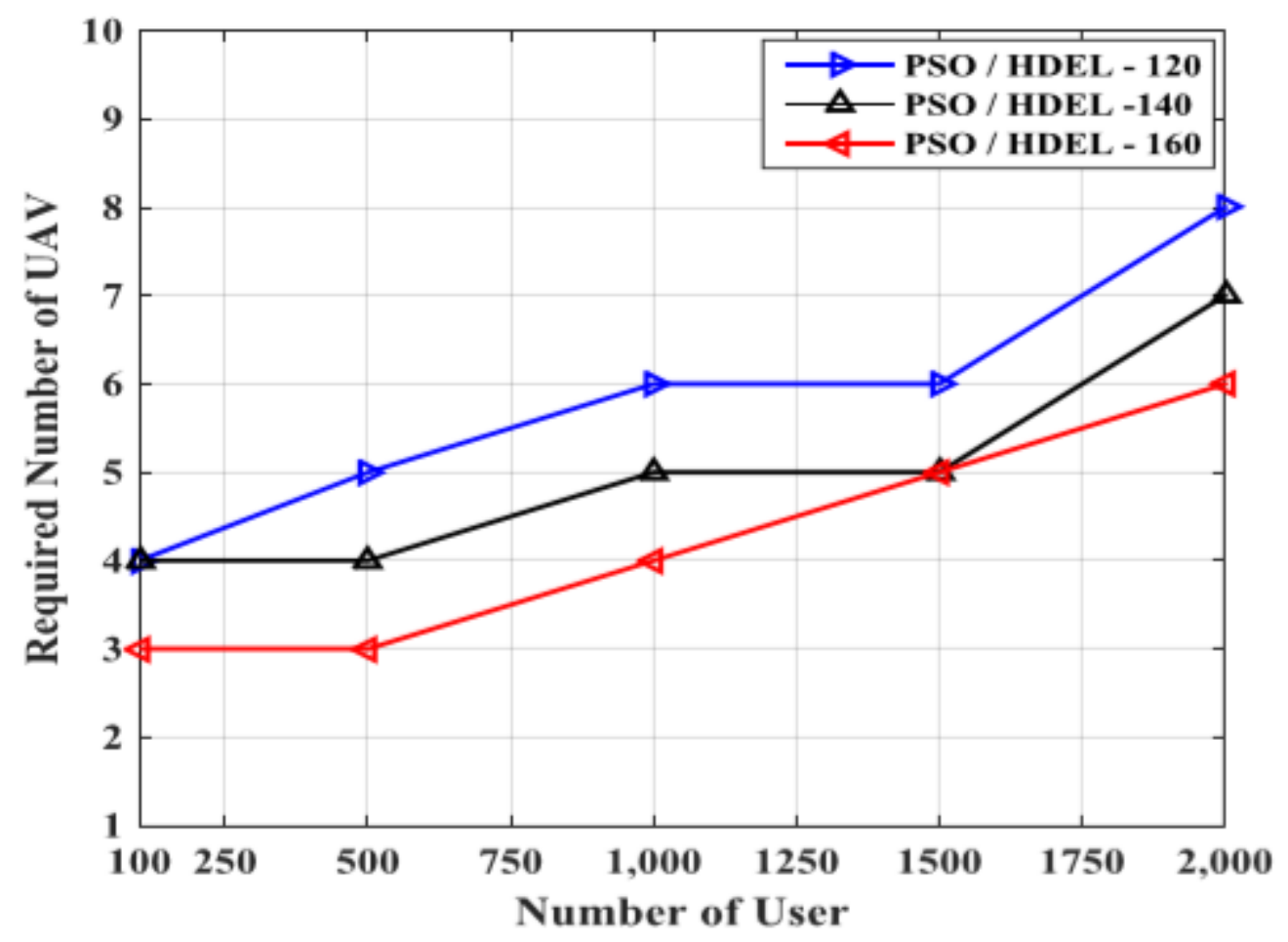

Figure 7

UAV required versus number of user in the area 


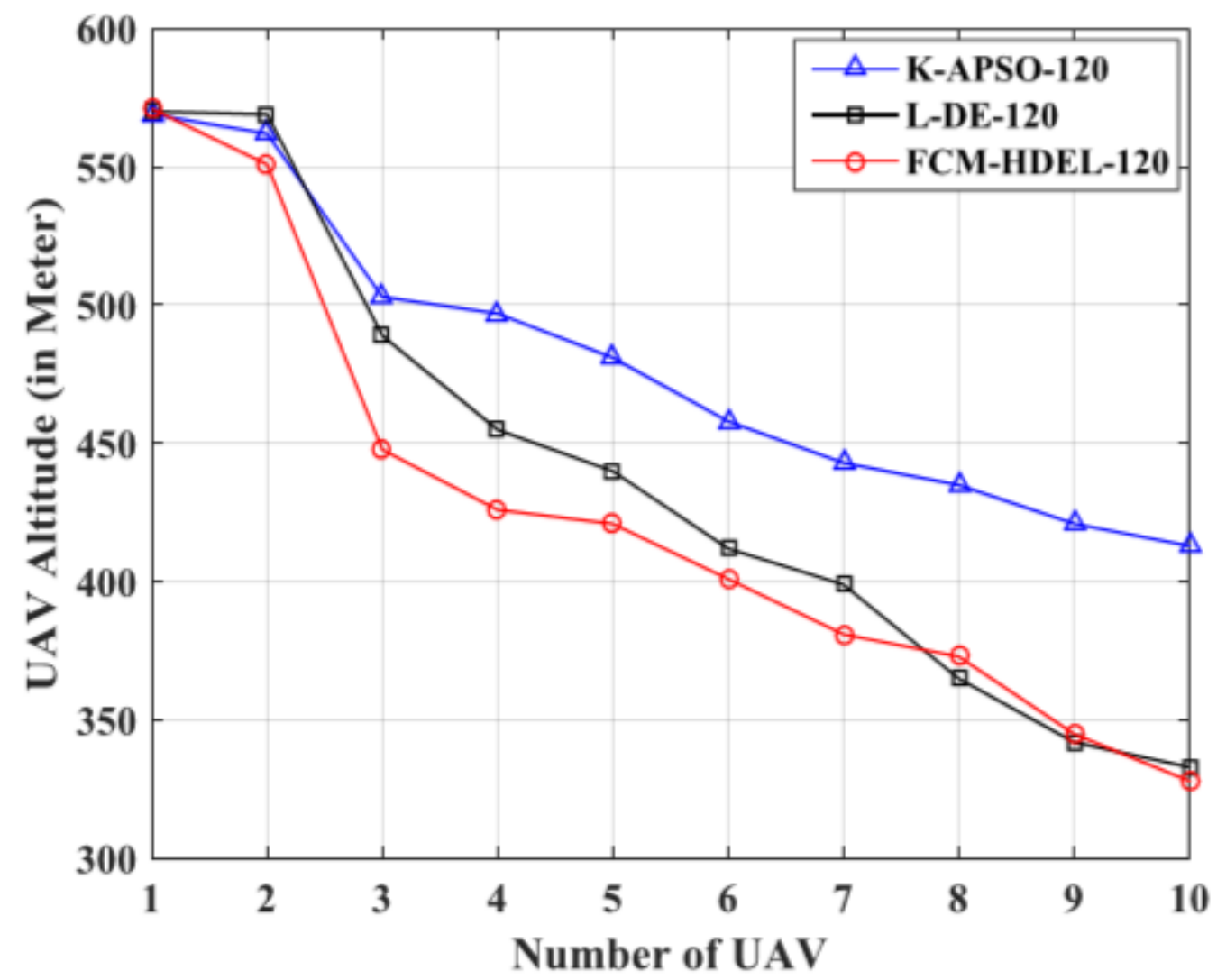

Figure 8

UAV attain altitude versus number of UAV in the considered area considering HPBW of antenna as 120 degree 


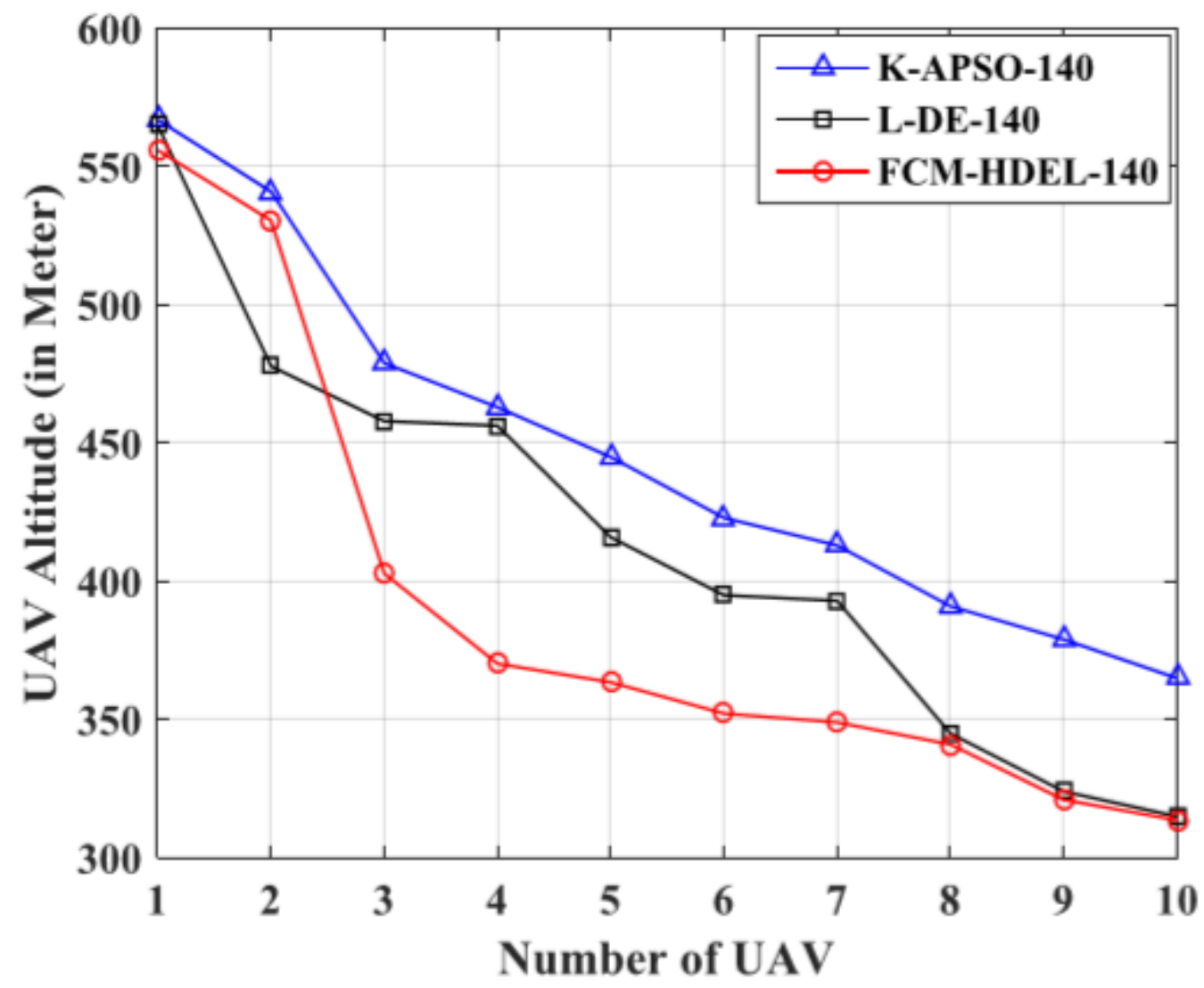

Figure 9

UAV attain altitude versus number of UAV in the considered area considering HPBW of antenna as 140 degree 


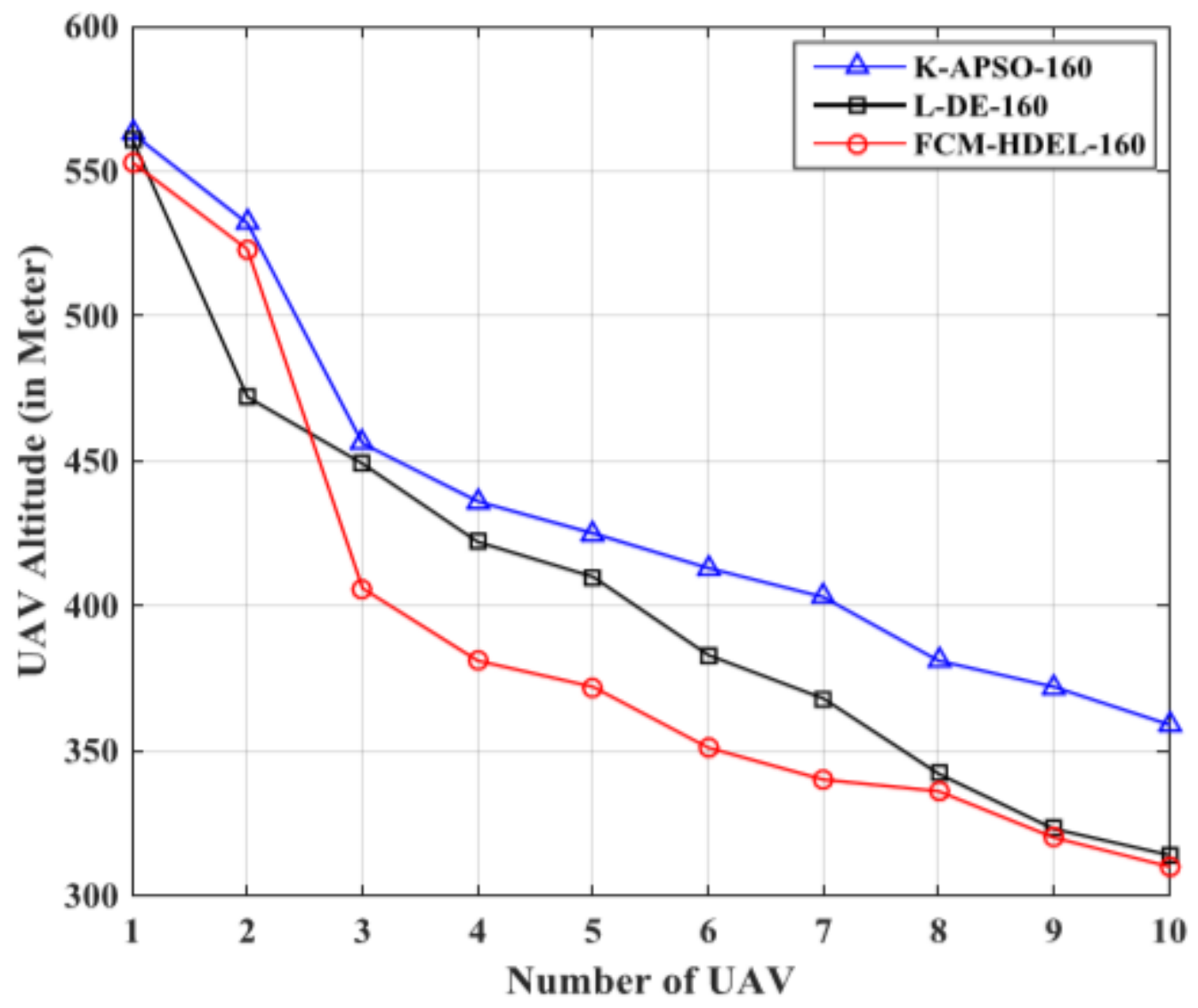

Figure 10

UAV attain altitude versus number of UAV in the considered area considering HPBW of antenna as 160 degree 


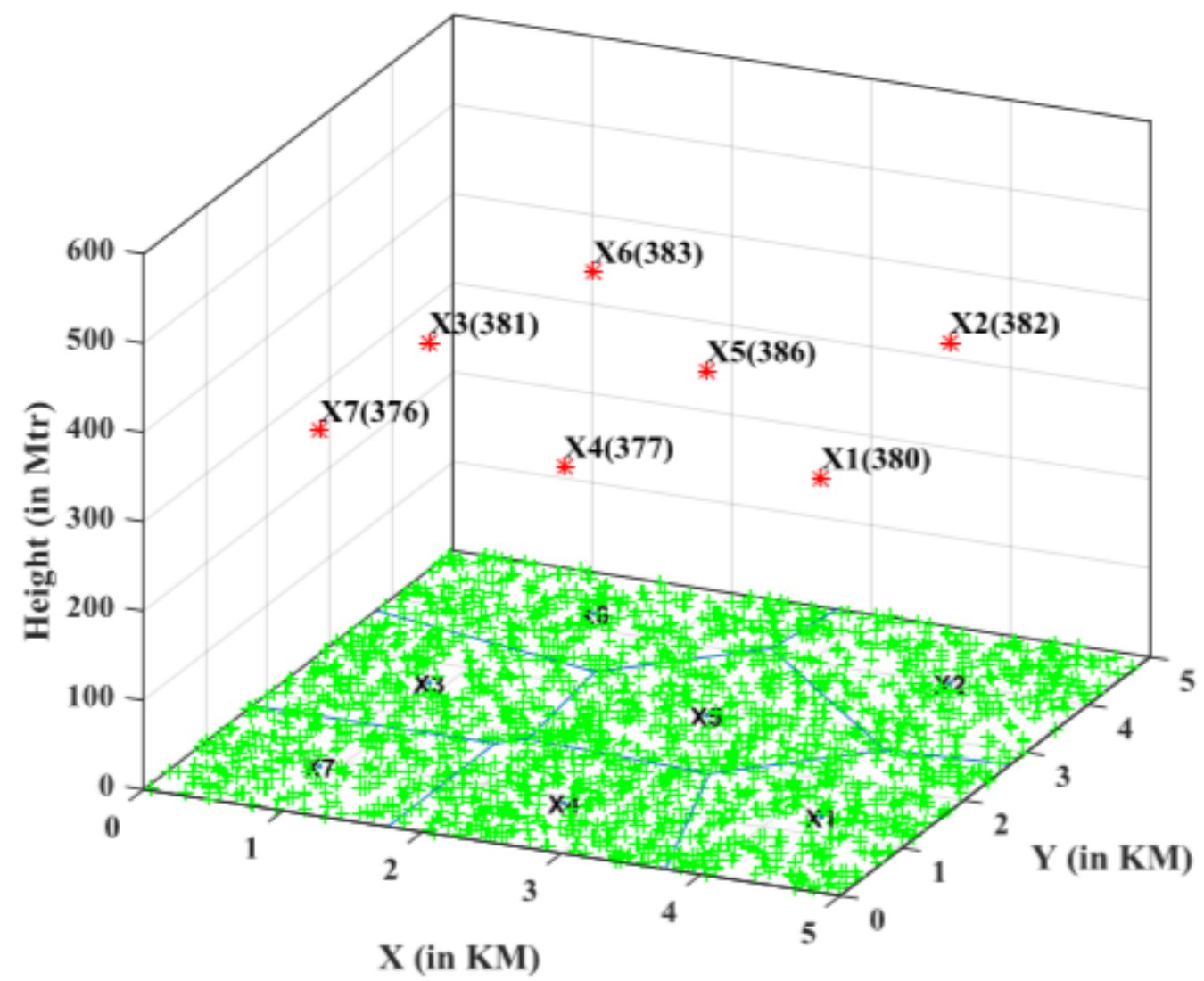

\section{Figure 11}

UAV planning for 2000 user and $20 \mathrm{MHz} B W$ in $700 \mathrm{MHz}$ Operating frequency

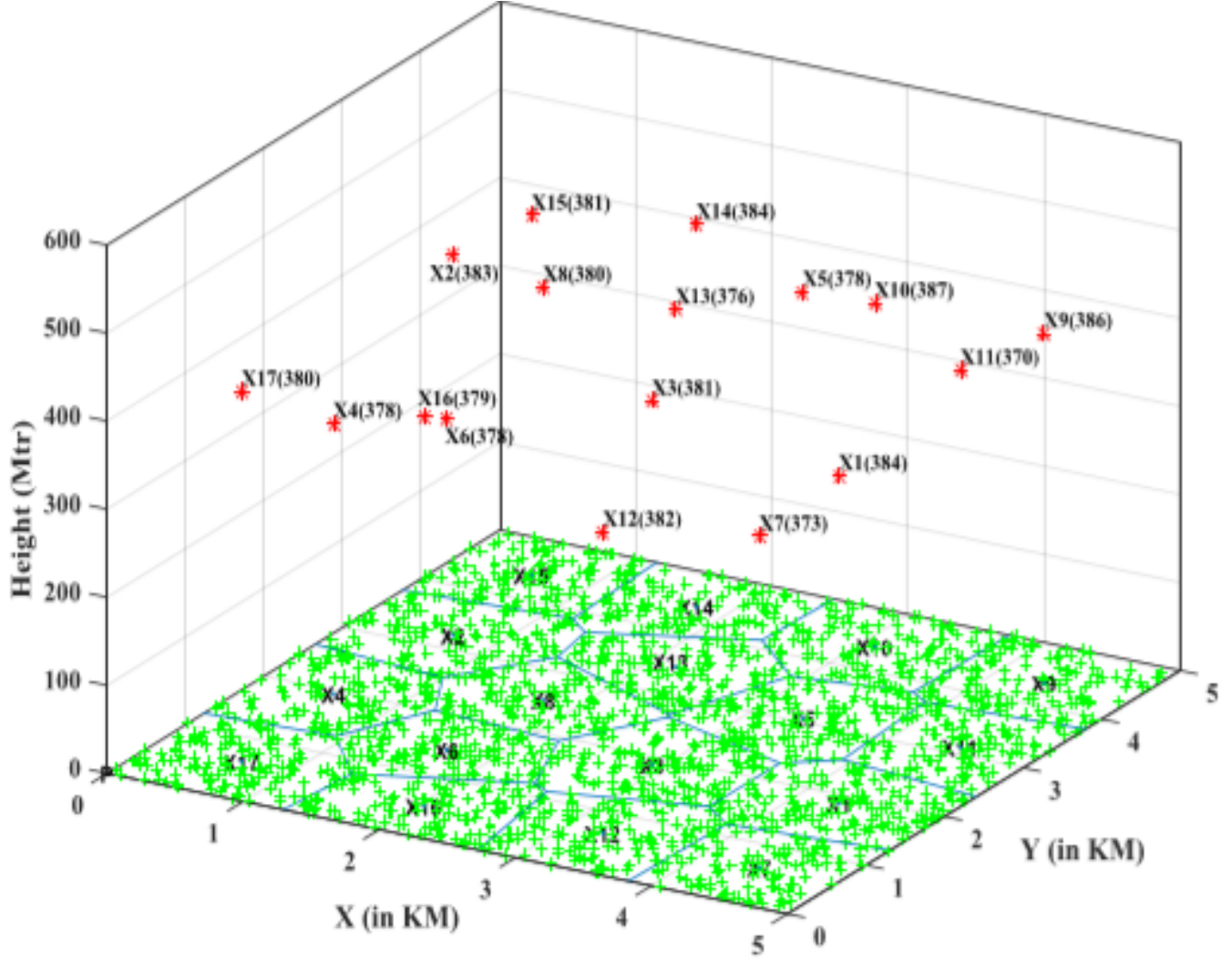


Figure 12

UAV planning in 3D for 2000 user and $20 \mathrm{MHz} B W$ in $1800 \mathrm{MHz}$ Operating frequency

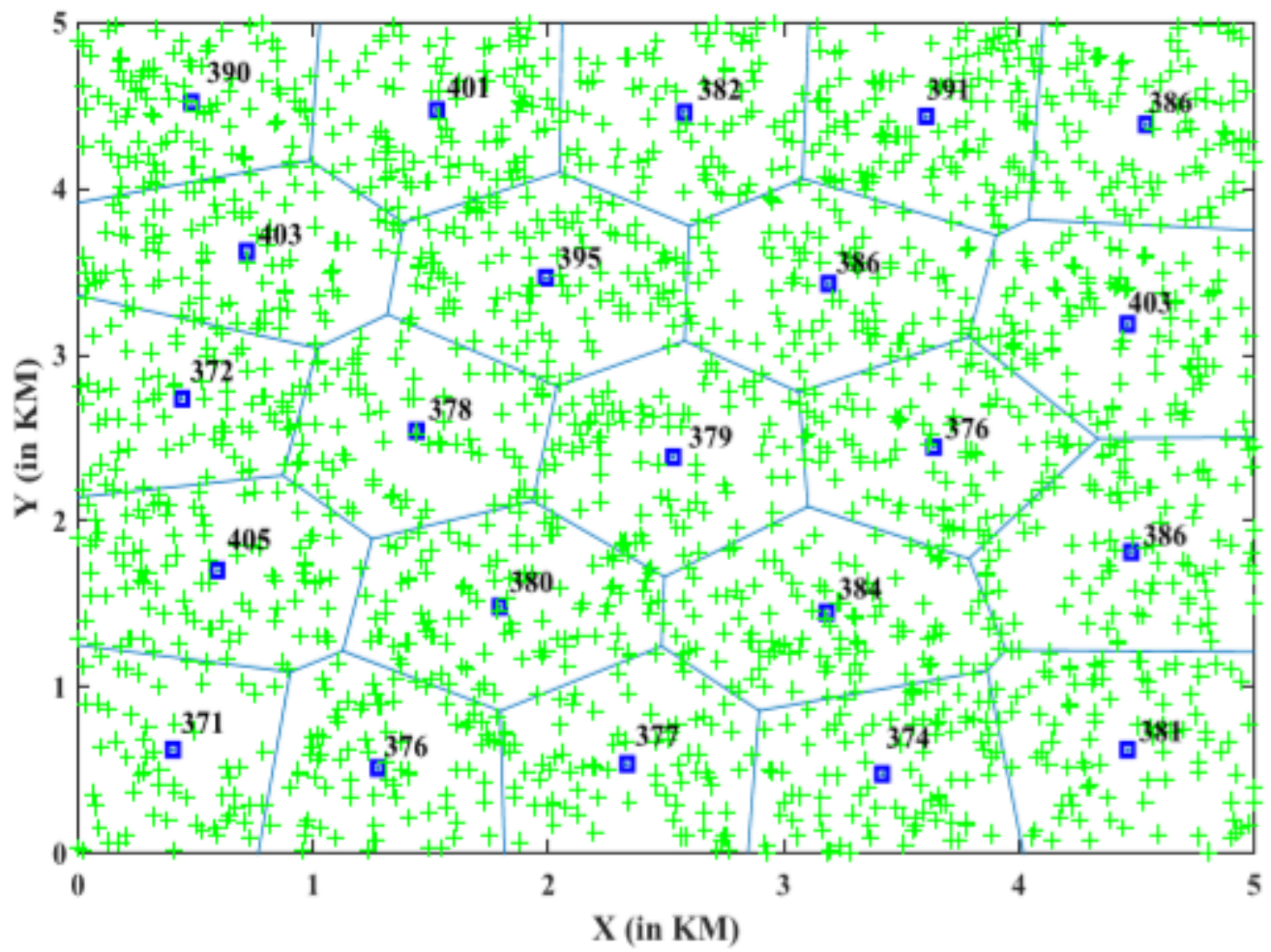

Figure 13

UAV planning for 2000 user and $20 \mathrm{MHz} B W$ in $2600 \mathrm{MHz}$ Operating frequency It 


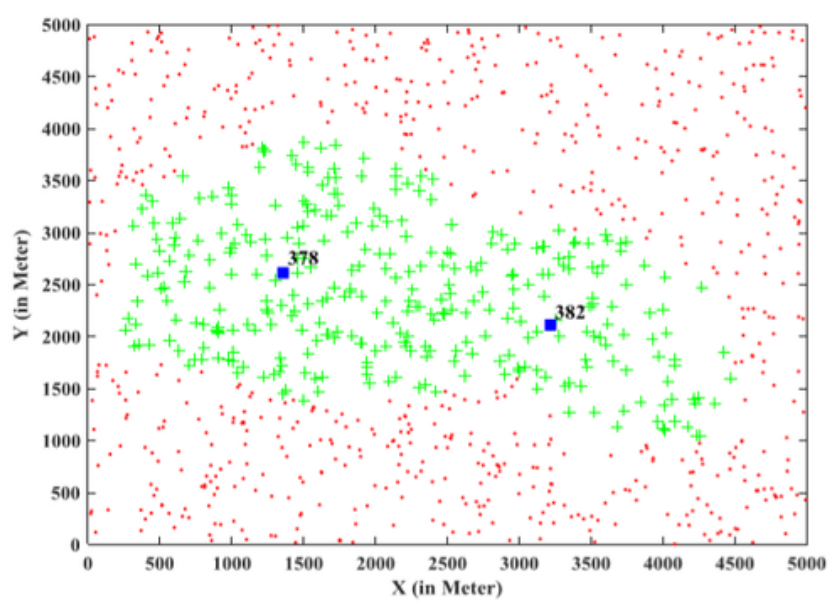

(a)

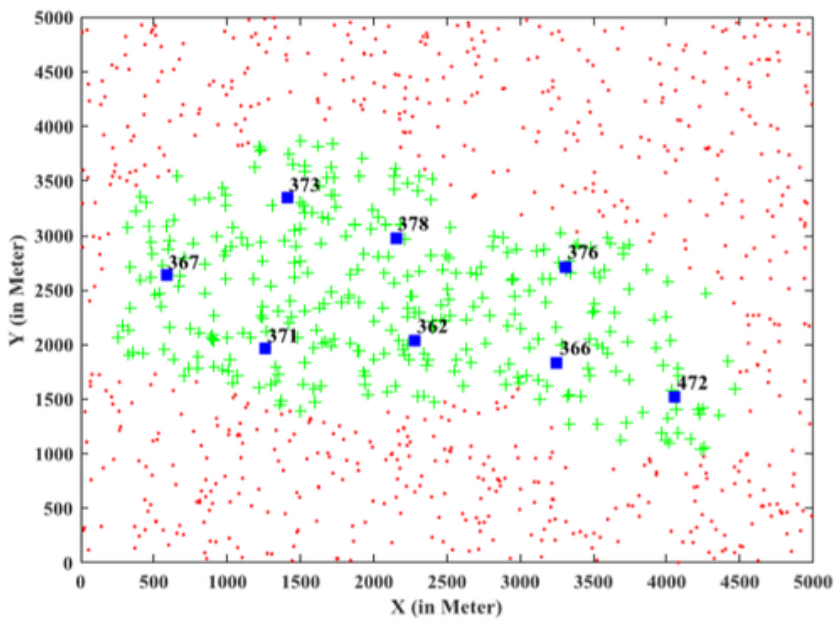

(b)

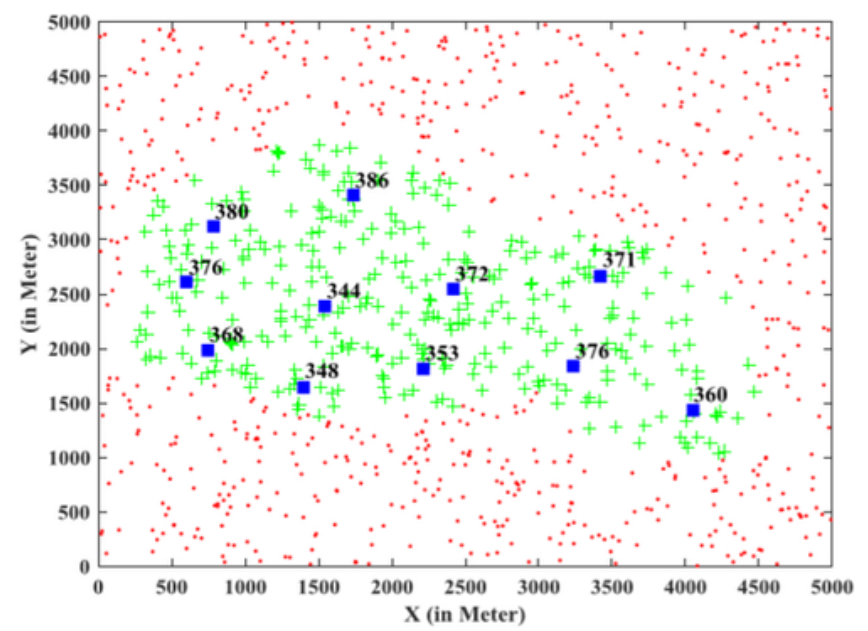

(c)

\section{Figure 14}

UAV Placement for considered blackout user coverage: User accessing $512 \mathrm{kbps}$ data rate in (a) $700 \mathrm{MHz}$ (b) $1800 \mathrm{MHz}$ and (c) $2600 \mathrm{MHz}$ operating frequency in Considered Disaster Area-I 


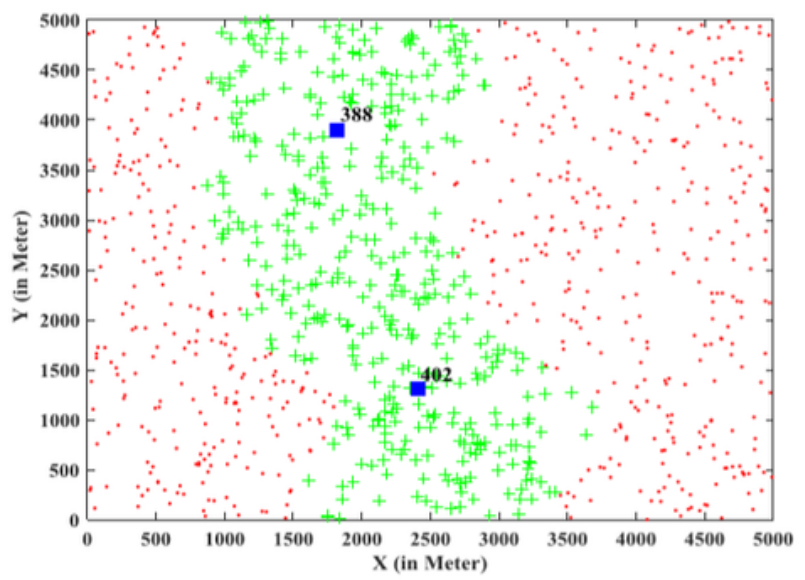

(a)

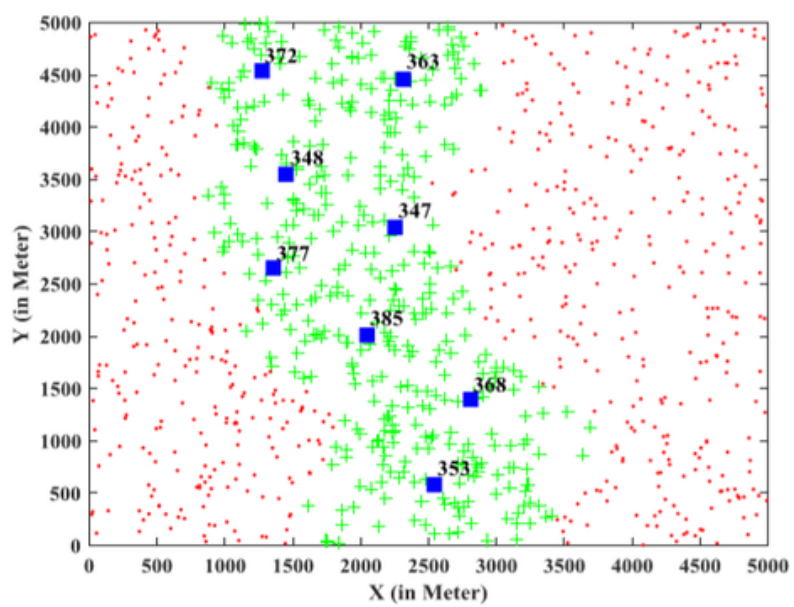

(b)

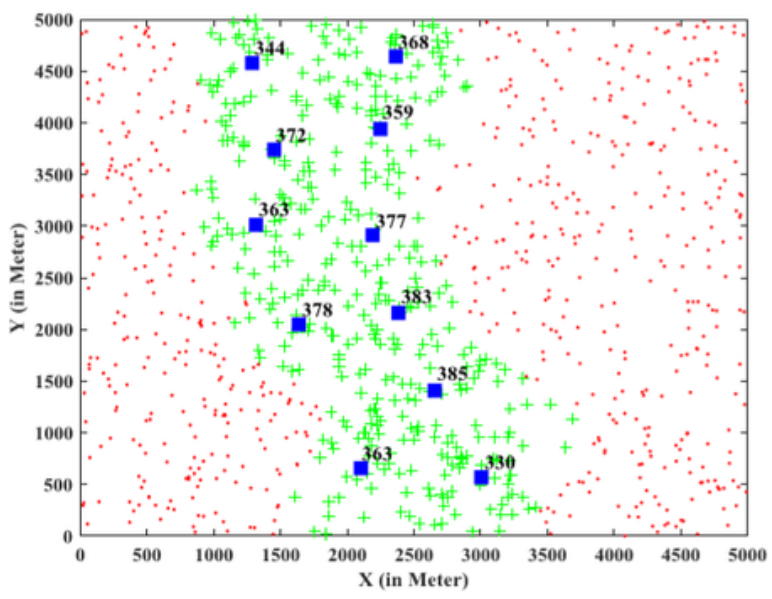

(c)

\section{Figure 15}

UAV Placement for considered blackout user coverage, User accessing $512 \mathrm{kbps}$ data rate in (a) $700 \mathrm{MHz}$ (b) $1800 \mathrm{MHz}$ and (c) $2600 \mathrm{MHz}$ operating frequency in Considered Disaster Area -II 


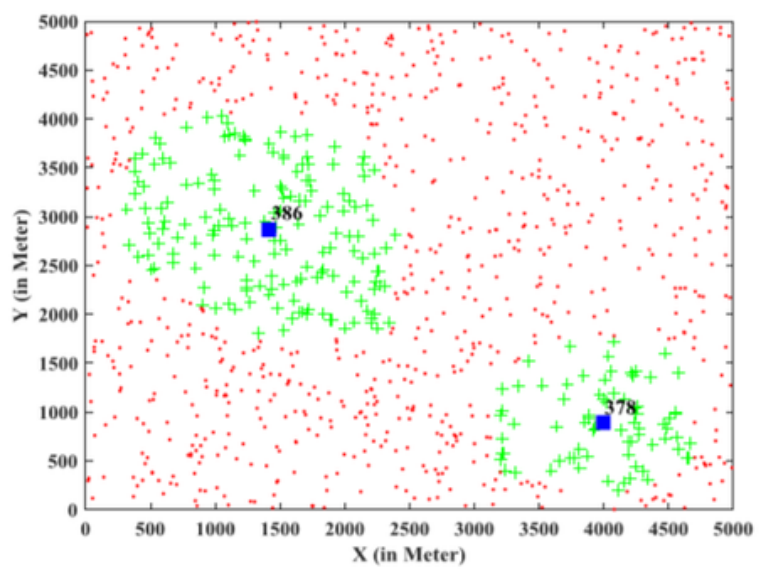

(a)

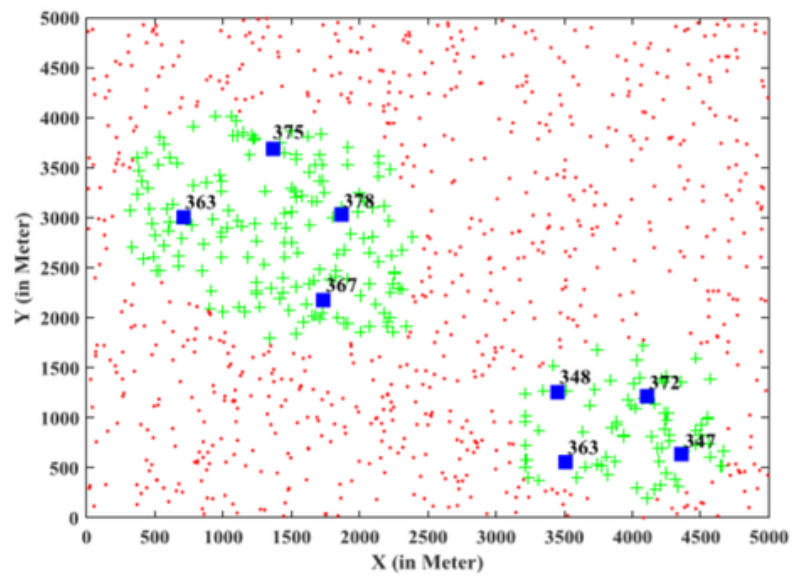

(b)

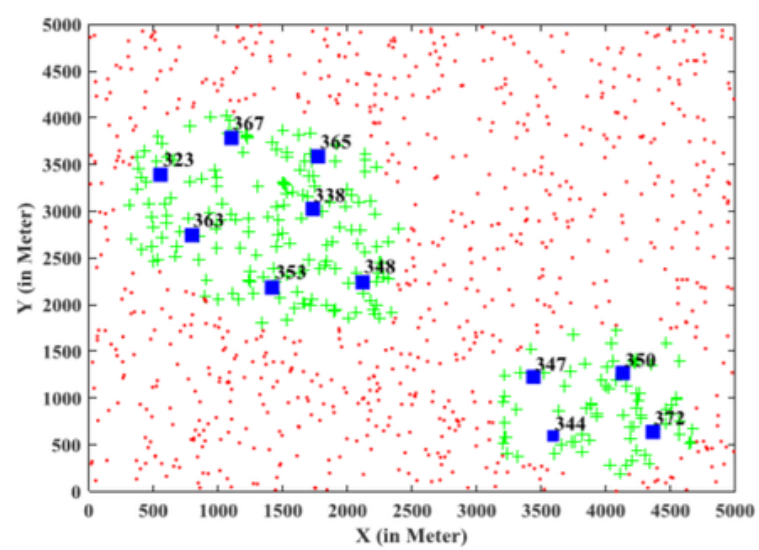

(c)

\section{Figure 16}

UAV Placement for considered blackout user coverage User accessing $512 \mathrm{kbps}$ data rate in (a) $700 \mathrm{MHz}$ (b) $1800 \mathrm{MHz}$ and (c) $2600 \mathrm{MHz}$ operating frequency in Considered Disaster Area -III 

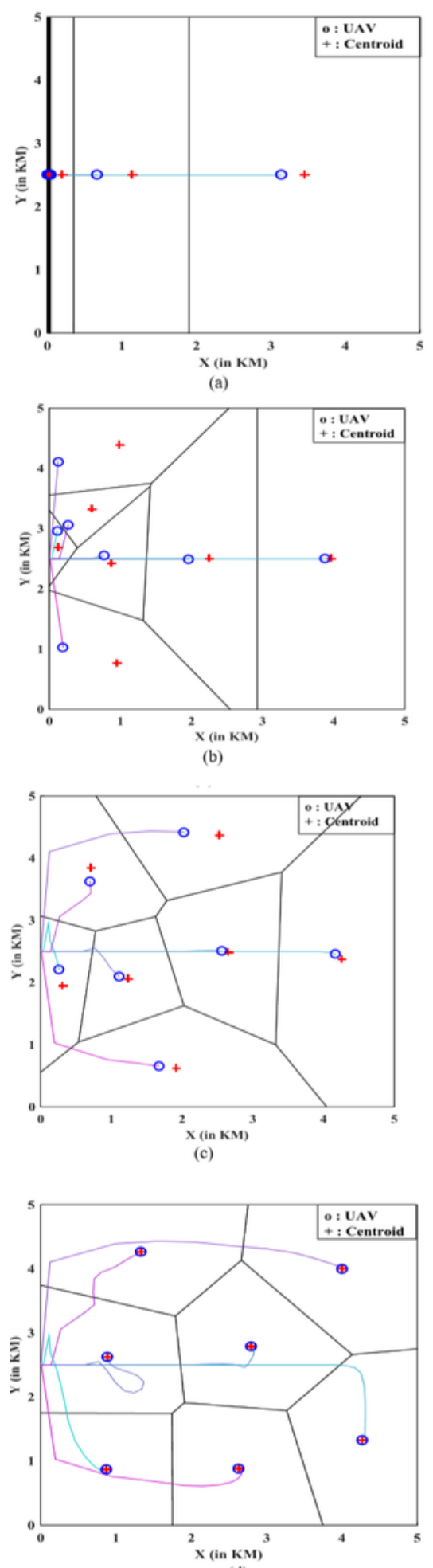

(d)

Figure 17

Trajectory path analysis for Scenario-l, (a) after 30.78 Seconds, (b) after 1.026 Minutes, (c) after 1.539 Minutes, and (d) after 2.05 Minutes 


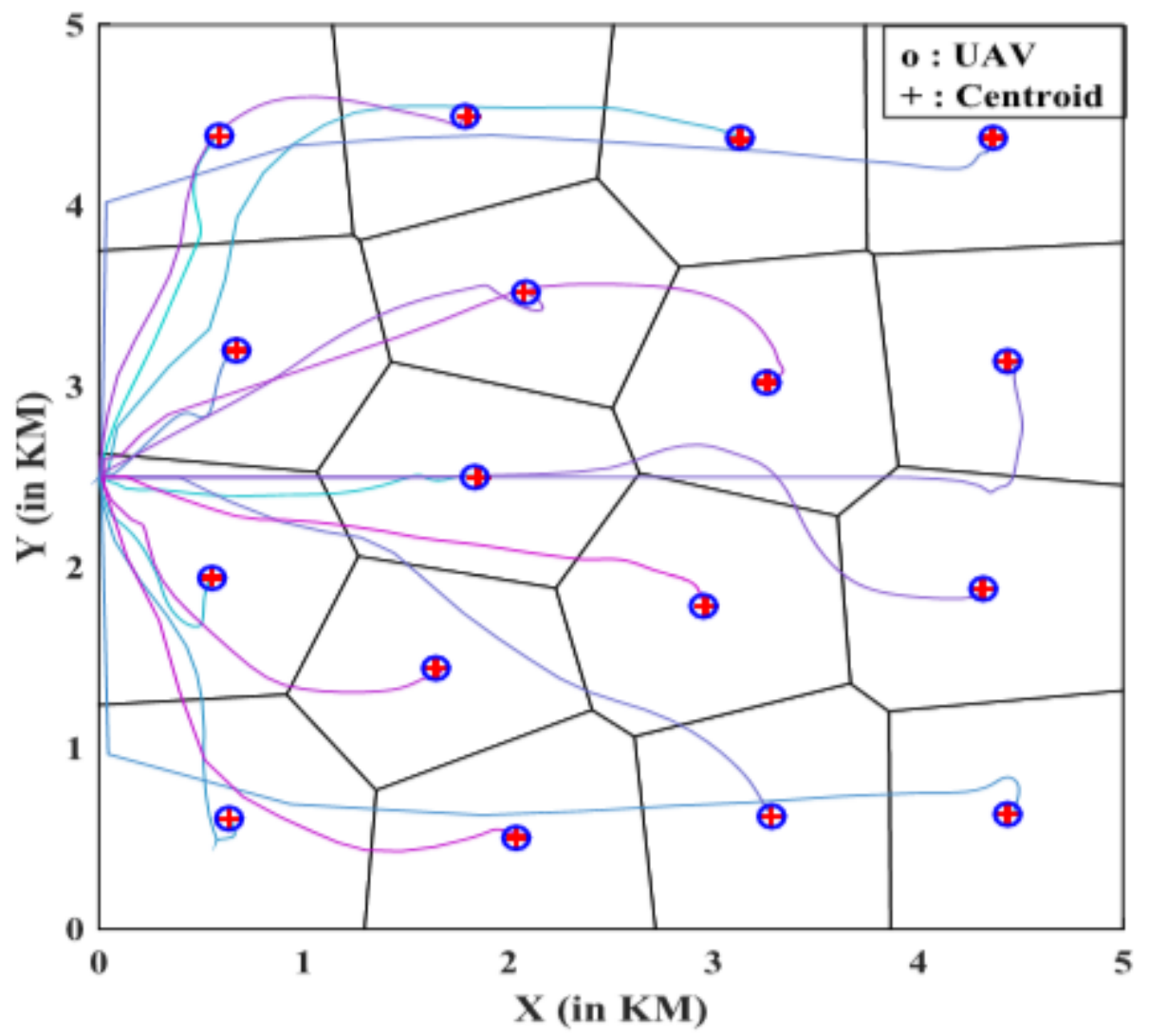

(a)

Figure 18

Trajectory path analysis for Scenario-II, after 2.12 Minutes. 


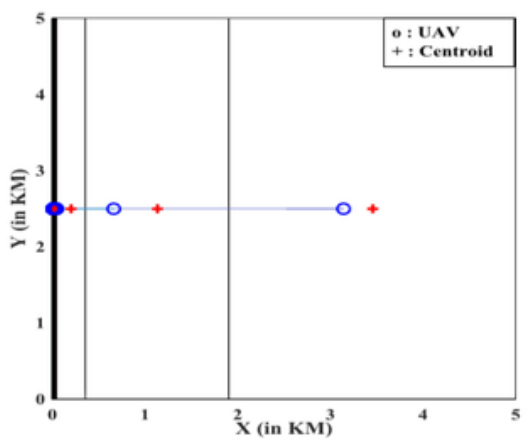

(a)
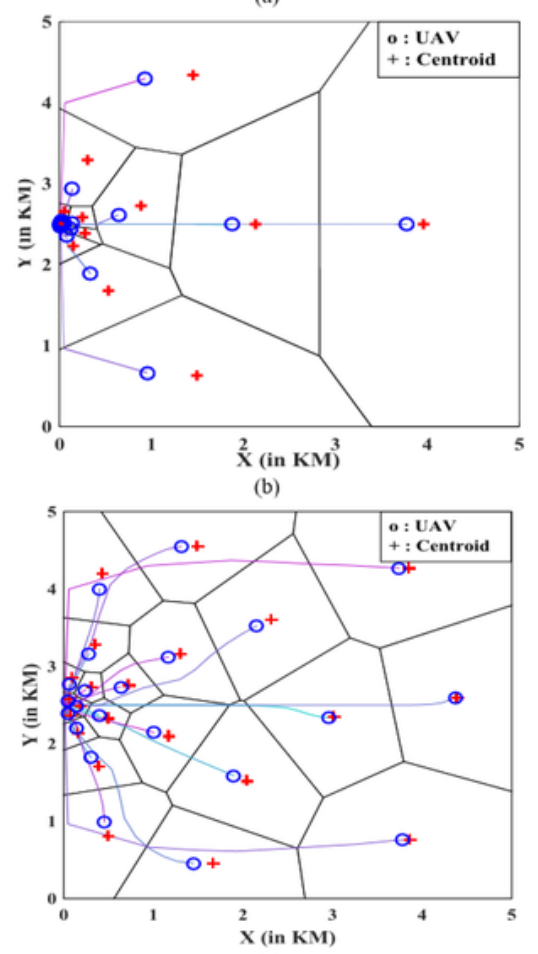

(c)

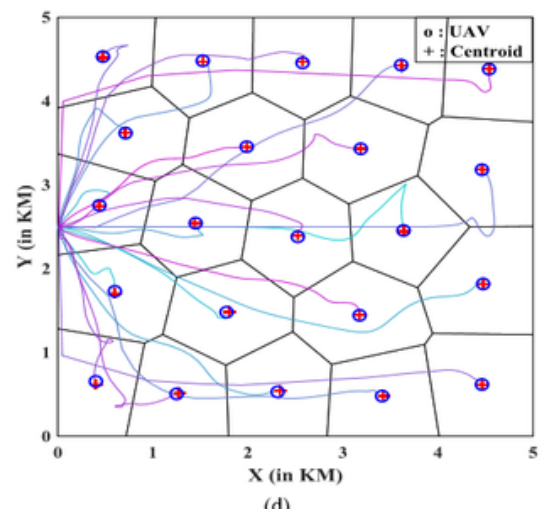

\section{Figure 19}

Trajectory path analysis for Scenario III, (a) after 45.75 Seconds, (b) after 1.53 Minutes, (c) after 2.29 Minutes, and (d) after 3.05 Minutes 